\title{
The effects of age of acquisition and word frequency on object naming accuracy in Alzheimer's disease Olga Lymperopoulou*1, Chris Barry ${ }^{2}$ and Paraskevi Sakka ${ }^{1}$
}

Address: ${ }^{1}$ Hygeia Hospital, Athens, Greece and ${ }^{2}$ University of Essex, UK

* Corresponding author

from International Society on Brain and Behaviour: 2nd International Congress on Brain and Behaviour Thessaloniki, Greece. 17-20 November 2005

Published: 28 February 2006

Annals of General Psychiatry 2006, 5(Suppl I):S76 doi:I0.II86/1744-859X-5-SI-S76

\section{Background}

In this study, we constructed a 60 -item picture set, comprising pictures that are culturally appropriate for the Greek population, which varied age of acquisition (AoA) and frequency in a fully-factorial design. Our main aim was to the effects of the above-mentioned factors on object naming accuracy in Alzheimer's disease.

\section{Materials and methods}

Values of written word frequency, rated AoA, rated concept familiarity, name agreement and word length were obtained for each item; it was found that almost all of them showed significant inter-correlations. The pictures were classified in four categories: a) early acquired-high frequency items, b) early acquired-low frequency items, c) later acquired-high frequency items and d) later acquiredlow frequency items. The picture set was presented to 55 patients suffering from dementia of Alzheimer's type (DAT) in order to examine the possible effects of word frequency and AoA on their naming accuracy, with several potentially confounding factors being accounted for.

\section{Results}

We found that their naming accuracy was affected by both word frequency and AoA, and further that there was an interaction between the two variables, with the frequency effect being larger for the early acquired words.

\section{Discussion}

To our knowledge, we are the first to report such a finding. This result could be attributed to the fact that previous studies have used heterogeneous groups of aphasic patients and hence, patterns of performance specific to DAT may have gone unnoticed; yet, the possibility of additional language-specific effects cannot be excluded.

\section{References}

I. Barry C, Morrison CM, Ellis AW: Naming the Snodgrass and Vanderwart pictures: effects of age of acquisition, frequency and name agreement. The Quarterly Journal of Experimental Psychology 1997, 50A:560-585.

2. Morrison CM, Chappell TD, Ellis AW: Age of acquisition norms for a large set of object names and their relation to adult estimates and other variables. The Quarterly Journal of Experimental Psychology 1997, 50A:528-559.

3. Barry C, Hirsh KW, Johnston RA, Williams CL: Age of acquisition, word frequency and the locus of repetition priming of picture naming. Journal of Memory and Language 200I, 44:350-375.

4. Snodgrass JG, Vanderwart M: A standardized set of 260 pictures: Norms for name agreement, image agreement, familiarity, and visual complexity. Journal of Experimental Psychology: Human Learning and Memory 1980, 6:174-215. 